\section{Desinfección de las impresiones dentales, soluciones desinfectantes y métodos de desinfección. Revisión de literatura}

\section{Disinfection of dental impressions, disinfectant solutions and disinfection methods. Literature review}

\section{Artículo de Revisión}

\author{
Carlos Alberto Arroyo Pérez ${ }^{1, a}$, Rosa Leonor Basauri \\ Esteves ${ }^{2, b}$, Jose Carlos Arroyo Moya ${ }^{3, c}$ \\ 1 Universidad Nacional Mayor de San Marcos, Facultad de \\ Odontología. Lima, Perú. \\ 2 Universidad Nacional de Trujillo, Facultad de Estomatología, \\ Trujillo, Perú. \\ ${ }^{3}$ Universidad Inca Garcilaso de la Vega, Facultad de Estoma- \\ tología, Lima, Perú. \\ a Magíster en Odontología. \\ ${ }^{\mathrm{b}}$ Doctora en Estomatología. \\ ${ }^{c}$ Bachiller en Estomatología.
}

\section{Correspondencia:}

Carlos Alberto Arroyo Pérez: carroyop@unmsm.edu.pe Av. Germán Amezaga № 375 - Ciudad Universitaria - 3er. Nivel Cercado de Lima, Lima Metropolitana (Perú).

ORCID: 0000-0002-4597-5237

\section{Coautores:}

Rosa Leonor Basauri Esteves: rosabaf6@hotmail.com ORCID: 0000-0001-5517-1702

José Carlos Arroyo Moya: josecarroyom@gmail.com

\section{Editor:}

Juan Carlos Cuevas-González

Universidad Autónoma de Ciudad Juárez, México.

\begin{abstract}
Resumen
La toma de impresiones en Odontología es un procedimiento frecuentemente realizado y su contaminación por microorganismos presentes en la flora bucal exige que sea sometida a un procedimiento de desinfección después de ser retirada de boca, para reducir al máximo los riesgos de infección cruzada tanto en la clínica como en el laboratorio. Las impresiones pueden ser fuente de transmisión de infecciones entre el odontólogo y el laboratorio debido al contacto con saliva y sangre del paciente, que luego infectan de forma cruzada los moldes de yeso. Se han descrito varios métodos de desinfección de impresiones en la literatura que tienen sus propias ventajas, desventajas y efectos sobre el material de impresión. Con el fin de mejorar el conocimiento y el comportamiento de los trabajadores de la salud dental con respecto a la desinfección de impresiones, en la presente revisión se sintetizan las técnicas de desinfección actuales así como sus efectos sobre la estabilidad dimensional y reproducción de detalles de los materiales de impresión. El uso de un desinfectante de nivel medio es recomendado por la Asociación Dental Americana, siendo los agentes químicos más accesibles que los agentes físicos por su fácil aplicación y menor costo. El desinfectante más recomendado es el hipoclorito de sodio al 5,25\%, debido a sus mínimas interacciones, su bajo precio y, aunque la solución es poco estable, su renovación es fácil y económica.
\end{abstract}

Palabras clave: Materiales de impresión dental; Desinfección; Hipoclorito de sodio; Modelos dentales (fuente: DeCS BIREME).

\footnotetext{
Abstract

Impression taking in dentistry is a frequent performed procedure and its contamination by microorganisms present in the oral flora requires that it be subjected to a disinfection procedure after being removed from the mouth, to minimize the risks of cross infection both in the clinic as in the laboratory. Impressions can be a source of infections transmission between the dentist and the laboratory due to the contact with saliva and blood of the patient, which then cross-infect the plaster casts. Several methods of impressions disinfection had been described in the literature that has their own advantages, disadvantages and effects on the impression material. In order to improve the knowledge and
}

Conflicto de intereses: los autores declaran no tener conflictos de interés.

Fuente de financiamiento: autofinanciado.

Recibido: $28 / 11 / 19$

Aceptado: 15/02/20

Publicado: 09/05/20 
behavior of dental health workers regarding the disinfection of impressions, the present review summarizes current disinfection techniques as well as their effects on dimensional stability and reproduction of details of impression materials: The use of a mid-level disinfectant is recommended by the American Dental Association, chemical agents being more accessible than physical agents because of their easy application and lower cost. The most recommended disinfectant is $5.25 \%$ sodium hypochlorite, due to the minimal interactions with impression materials, although the solution is not very stable, it is economical and easy to obtain.

Keywords: Dental impression materials; Disinfection; Sodium hypochlorite; Dental models (source: MeSH NLM).

\section{Introducción}

Desinfectar las impresiones dentales es parte de la rutina odontológica para proteger al personal que manipula los modelos e impresiones frente a infecciones cruzadas como hepatitis B, hepatitis C, herpes, VIH (virus de la inmunodeficiencia humana), Mycobacterium tuberculosis, entre otros. Esto debido a que las impresiones se ven expuestas a cantidades considerables de saliva y/o sangre del paciente.

Es recomendable que las impresiones sean desinfectadas y descontaminadas antes de ser remitidas al laboratorio, asimismo sean etiquetadas y empaquetadas como un procedimiento de responsabilidad del odontólogo ${ }^{1}$. El no realizarlo convierte a las impresiones en fuentes transmisoras de bacterias y virus entre clínicas y laboratorios dentales ${ }^{2}$, de la misma forma, los modelos de yeso pueden transportar microorganismos y estos pueden extenderse a otras partes del consultorio o del laboratorio, durante el recorte de los modelos ${ }^{3}$. Es recomendable que el odontólogo envíe una etiqueta que indique el estado de las impresiones como "impresiones desinfectadas" para proteger la estabilidad dimensional y reproducción de los detalles de la superficie de las impresiones. Esta práctica puede eliminar posibles incertidumbres que enfrentan los técnicos dentales cuando reciben las impresiones y evitar la desinfección repetitiva ${ }^{4,5}$.

Químicamente, los materiales de impresión presentan un componente orgánico que requiere de agua para el proceso de reticulación; otros captan agua para movilizar a sus agentes por lo que son en menor o mayor medida hidrofílicos, esto los hace sensibles al crecimiento microbiano. Con el paso del tiempo, la superficie húmeda puede convertirse en un vehículo de contaminación de los yesos aumentando el riesgo de contaminación cruzada ${ }^{6}$. Existen variadas alternativas de agentes químicos que pueden ser utilizadas para la desinfección de las impresiones. También se ha reportado que el enjuague con agua no elimina los agentes contaminantes ${ }^{7}$, por lo que se requiere el uso de desinfectantes. Como la desinfección química es un fenómeno superficial, es importante que antes de la inmersión en el desinfectante, las impresiones sean lavadas para eliminar los restos de mayor tamaño y maximizar el efecto de la solución desinfectante ${ }^{7}$. Una recomendación práctica acorde a distintos estudios es la de establecer una comunicación entre los laboratorios dentales y los dentistas para garantizar una limpieza adecuada de las impresiones ${ }^{8}$.

En la cavidad bucal existen alrededor de 700 especies de bacterias, algunas son patógenas oportunistas como en la gingivitis o la periodontitis, por ello la contaminación cruzada es un riesgo que el odontólogo puede provocar debido a que frecuentemente toma impresiones bucales ${ }^{8}$. La efectividad del desinfectante dependerá del tiempo de exposición, concentración, concentración del germen y cantidad de residuo presente en el material ${ }^{8,9}$. La desconfianza entre los técnicos dentales y los dentistas podría resultar en la repetición de procedimientos de desinfección de la impresión por parte del técnico incluso después de ser desinfectados por el odontólogo, esto puede afectar los cambios dimensionales y alterar la precisión del material de impresión ${ }^{10}$.

Por tal motivo, el objetivo del presente trabajo es presentar evidencia científica sobre los procedimientos de desinfección de las impresiones bucales en Odontología y algunas consideraciones sobre los materiales de impresión. En una primera parte se expone las características de los materiales de impresión para obtener un panorama general de sus propiedades; las cuales podrían verse afectadas por el procedimiento, sin embargo, el énfasis continuará con los resultados de diversos estudios que valoraron el efecto de los agentes desinfectantes y su efecto sobre la estabilidad dimensional de los materiales de impresión.

\section{Materiales de impresión}

Los registros de impresión dental son procedimientos que deben realizarse de forma adecuada para permitir la obtención de modelos definitivos óptimos, que puedan ser de utilidad para el correcto diagnóstico y/o tratamiento. Existen diferentes materiales de impresión disponibles en el mercado, de los cuales los más utilizados son los hidrocoloides irreversibles (alginato), principalmente por su facilidad de manejo y bajo costo.

Los materiales se preparan al mezclar dos componentes hasta lograr una pasta homogénea que endurecerá paulatinamente. La función de los materiales de impresión es la de reproducir en negativo las estructuras bucales que se requiere trabajar en un laboratorio dental. El material debe ser capaz de reproducir fielmente las estructuras sin producir burbujas, distorsionar las dimensiones, provocar desgarros o afectarse debido a las condiciones del 
medio ambiente ${ }^{11,12}$. Se clasifican según su propiedades físicas en rígidos, termoplásticos y elásticos ${ }^{13}$ (Tabla 1).

Tabla 1. Clasificación de los materiales de impresión según sus propiedades físicas

\begin{tabular}{ll}
\hline Clasificación & Tipos \\
\hline Rígidos & 1.1 Yesos para impresiones \\
& 1.2 Compuesto zinquenólicos \\
Termoplásticos & 2.1 Cera para impresiones \\
& 2.2 compuesto para modelar \\
Elásticos & 3.1 Hidrocoloide irreversible (alginato) \\
& 3.2 Hidrocoloide reversible (agar) \\
& 3.3 Polisulfuros \\
& 3.4 Siliconas \\
&
\end{tabular}

Los alginatos o hidrocoloides irreversibles son los materiales de impresión más utilizados en la toma de impresiones preliminares de la cavidad bucal principalmente en las especialidades de prótesis fija, prótesis removible y ortodoncia; debido a su fácil manipulación, bajo costo, comodidad para el paciente y no requerir de equipo especial para su uso ${ }^{14}$. Sin embargo, durante la gelificación del alginato, las dimensiones de esta impresión pueden verse alteradas por distintos factores externos, como: tiempos de vaciado, condiciones de almacenamiento, uso de agentes desinfectantes y variaciones de las proporciones utilizadas, las cuales pueden afectar al modelo en positivo (vaciado en yeso) obtenido de dicha impresión ${ }^{15,16}$.

La estabilidad dimensional del hidrocoloide irreversible se ve afectada por dos fenómenos: la imbibición (ganancia de agua por mantener la impresión en un ambiente húmedo o agregándole líquidos al momento de lavar o desinfectar) y la sinéresis (pérdida de agua por la exposición prolongada de la impresión al ambiente), procesos que dependen de factores externos, como la temperatura del ambiente, la humedad del ambiente, el almacenamiento por un tiempo prologando, se conoce por ejemplo que a mayor tiempo transcurrido desde la toma de impresión, mayor será el cambio dimensional en el alginato ${ }^{15}$. Existen diferentes presentaciones y modificaciones que le dan al alginato otras propiedades que facilitan su manejo, por ejemplo las presentaciones cromáticas facilitan la identificación de los tiempos de gelificación por parte del odontólogo, algunos autores mencionan que los cambios dimensionales durante la gelificación varían según la marca comercial ${ }^{16}$.

Hoy en día existe una predilección por el uso de materiales elastoméricos debido a su mayor precisión y estabilidad dimensional al ser comparado con otros materiales. En los años 1950 aparecieron los polisulfuros para luego ser introducidas las siliconas de condensación. En los años 1960 a 1970 aparecen los poliéteres junto con las siliconas por adición ${ }^{17}$.

\section{Niveles de desinfección}

La eficacia de los desinfectantes químicos contra esporas bacterianas, bacilo de la tuberculosis, esporas de hongos y virus permite clasificarlos en tres categorías: alto nivel, nivel intermedio y bajo nivel. Los de alto nivel son capaces de inactivar las esporas bacterianas y todas las demás formas microbianas, entre ellas se encuentran el gas de óxido de etileno y las soluciones de glutaraldehido. Entre los de nivel intermedio se encuentran el formaldehído, compuestos de cloro, yodóforos, alcoholes y compuestos fenólicos, los cuales destruyen los microbios, como los bacilos de tuberculosis, pero no inactivan las esporas. Los de bajo nivel son agentes químicos con actividad antibacteriana limitada y entre ellos se encuentran a los compuestos de amonio cuaternario, fenoles simples y detergentes, que no son deseables para la desinfección de impresiones ${ }^{17}$; se resume en la tabla 2 los principales niveles de desinfección y su relación con los desinfectantes utilizados en los materiales de impresión.

Durante el ejercicio clínico odontológico, por distintos motivos el vaciado de yeso en las impresiones es postergado, lo cual altera las dimensiones obtenidas en los modelos, alterando así los resultados que se puedan obtener de los análisis de dichos modelos.

Estas impresiones dentales también deben ser desinfectadas para mantener una correcta cadena de asepsia y antisepsia, y así evitar las infecciones cruzadas entre paciente y odontólogo, paciente y asistente dental o entre paciente y técnico dental, quienes son las personas

Tabla 2. Niveles de desinfección según desinfectante y tipo de material de impresión. Fuente: Adaptado de Mushtaq y Ullah ${ }^{17}$

\begin{tabular}{|c|c|c|c|}
\hline Nivel de desinfección & Desinfectante & Tipo de material de impresión & Tiempo de exposición \\
\hline Alto nivel & Glutaraldehido & $\begin{array}{l}\text { Hidrocoloide irreversible } \\
\text { Óxido de zinc eugenol } \\
\text { Poliéter y polisulfuro } \\
\text { Silicona de adición }\end{array}$ & 10 minutos \\
\hline Nivel intermedio & $\begin{array}{l}\text { Hipoclorito de sodio } \\
\text { Complejo iodoformados } \\
\text { Fenoles } \\
\text { Clorhexidina } \\
\text { Alcoholes }\end{array}$ & $\begin{array}{l}\text { Hidrocoloide irreversible } \\
\text { Óxido de zinc eugenol } \\
\text { Poliéter y polisulfuro } \\
\text { Silicona de adición } \\
\text { Compuestos de impresión }\end{array}$ & 10 minutos \\
\hline Bajo nivel & $\begin{array}{l}\text { Compuestos de amonio cuaternario } \\
\text { Detergentes fenólicos simples }\end{array}$ & No se recomienda su desinfección & 10 minutos \\
\hline
\end{tabular}


que manipulan la impresión después de ser obtenida ${ }^{17}$. Pero este proceso de desinfección trae consigo una posible consecuencia, las sustancias desinfectantes utilizadas en Odontología vienen en presentación líquida, y al ser aplicadas sobre las impresiones, estas afectarían su estabilidad dimensional.

\section{Soluciones desinfectantes y métodos de desinfección para los materiales de impresión}

Yodoformo. Los yodoformos son generalmente aceptados como agentes antibacterianos para muchos propósitos. Varios estudios han evaluado la eficacia germicida de los yodoformos de alta concentración, sin embargo esta alta concentración crean cierta resistencia entre los usuarios debido al olor del producto y el color cuando se aplica a la piel ${ }^{18}$. El yodo deriva gran parte de su utilidad clínica por la combinación de su baja toxicidad, alto peso molecular y facilidad de reactividad con moléculas. De igual forma que el flúor, el cloro y el bromo, el yodo es un poderoso agente oxidante y su efecto antiséptico en preparaciones medicinales se reconoció poco después de su descubrimiento; sin embargo su uso generalizado tuvo limitaciones debido a su baja solubilidad acuosa, y limitada estabilidad química, pues se neutraliza en presencia de material orgánico, y sumado a esto, su alta toxicidad local ${ }^{19}$.

Glutaraldehido. El glutaraldehido es un aceite incoloro y penetrante, utilizado como desinfectante y esterilizante químico y muy popular para la desinfección de impresiones dentales. Tiene actividad bactericida, virucida, fungicida, esporicida y parasiticida y se debe a la alquilación de los grupos hidroxilo, carbonilo y amino, lo que afecta al ADN (ácido desoxirribonucleico), ARN (ácido ribonucleico) y síntesis de proteína de los microorganismos. El glutaraldehido se une fuertemente a la membrana externa de las bacterias, inhibiendo el transporte de membrana y pierde su actividad cuando está en soluciones acuosas ácidas, sin embargo, cuando se activa a $\mathrm{pH} 7,5-8,5$, la solución se vuelve biocida y pueden ser altamente tóxicos ${ }^{20}$.

Hipoclorito de sodio ( $\mathrm{NaOCl})$. Es un agente desinfectante muy usado en Odontología para la desinfección de materiales de impresión, por su actividad antimicrobiana efectiva, su capacidad para disolver tejidos orgánicos y bajo costo, combinado con la fácil disponibilidad. La capacidad de disolución de tejidos que tiene el $\mathrm{NaO}$ $\mathrm{Cl}$ está directamente relacionada con su concentración, la que también le confiere su acción irritante sobre los tejidos ${ }^{21}$. Su excelente actividad proteolítica y antimicrobiana se debe a su acción de cloraminación, neutralización de aminoácidos y reacción de saponificación. Aunque tiene muchas ventajas, carece de estabilidad química en presencia de la luz, aire, cambio de $\mathrm{pH}$ y contaminantes orgánicos e inorgánicos, lo que produce la descomposición de iones de hipoclorito en clorato y iones de cloro. $\mathrm{Al}$ respecto numerosos investigadores estudiaron esta situación encontrándose que el $\mathrm{NaOCl}$ se puede mantener estable durante semanas y hasta meses, sin embargo la literatura recomienda que para la eficacia antimicrobiana, se debe preparar una solución fresca de $\mathrm{NaOCl}$.

La solución de $\mathrm{NaOCl}$ es más estable a $\mathrm{pH} 11$ y superior a ella. A medida que el $\mathrm{pH}$ disminuye de 11 a 7, la descomposición también aumenta y es más alta a $\mathrm{pH}$ 7. Por lo tanto, el pH óptimo y la concentración de cloro de la solución $\mathrm{NaOCl}$ son muy importantes para su efectividad ${ }^{22}$.

Cloruro de benzalconio. El cloruro de benzalconio nace después de muchas modificaciones a las fórmulas de compuestos de amonio cuaternario, que se han hecho con la esperanza de aumentar su ya potente actividad antimicrobiana. El cloruro de benzalconio, es una sal de cloruro de amonio cuaternario de acción antibacteriana, antiséptica, detergente y surfactante; no es efectivo contra virus, hongos, y esporas bacterianas; y posee un mecanismo de actividad antimicrobiana basado esencialmente en la alteración de la bicapa de fosfolípidos de la membrana celular y la alteración y desnaturalización de proteínas estructurales y enzimas ${ }^{23}$.

El cloruro de benzalconio, es pues, un excipiente de amonio cuaternario, que tiene tres aplicaciones principales: como biocida, agente tensioactivo catiónico y agente de transferencia de fase en la industria química, por ello, sus aplicaciones son extremadamente amplias, desde desinfectantes microbianos hasta prevención en la industria de servicios petroleros ${ }^{24}$.

Alcohol isopropílico y alcohol etílico. El alcohol isopropílico es un compuesto químico incoloro con un fuerte olor. Su utilización comúnmente es como antiséptico tópico, aunque también se usa para desinfectar la superficie de los equipos médicos. Como todos los alcoholes, son inflamables, por ello, deben almacenarse en un área fresca y bien ventilada. Es irritante tisular y se evapora rápidamente. Es muy caro para uso general como desinfectante de superficie ${ }^{17}$.

El alcohol etílico es más bactericida que bacteriostático, también es fungicida y virucida en aquellos virus con envoltura, no así en aquellos que tienen envoltura; tampoco es efectivo contra las esporas; pero si es tuberculicida. Actúan desnaturalizando las proteínas bacterianas. La concentración bactericida óptima en agua es de 60\% a $90 \%$, y la actividad disminuye cuando se diluye por debajo del $50 \%$ de concentración. El etanol, en altas concentraciones, ha mostrado una inhibición clara del crecimiento bacteriano, del $S$. mutans y $S$. aureus ${ }^{17}$.

Clorhexidina. El digluconato de clorhexidina es una bis-biguanida, que cuando se usa en altas concentraciones, tiene un efecto bactericida inmediato, si se utilizan concentraciones más bajas, tiene un efecto bacteriostático. Las moléculas de clorhexidina cargadas positivamente se unen fácilmente a la pared celular bacteriana que está cargada negativamente, interfiriendo así con el transporte de la membrana, produciendo fuga de sustancias de bajo peso molecular a través de ella y produciendo la precipitación del citoplasma ${ }^{25}$. 
Agua ozonizada. El ozono es un alótropo de oxígeno; es un gas inestable muy conocido por sus efectos antimicrobianos y ha sido utilizado como un desinfectante para aplicaciones tales como la desinfección del agua y la esterilización de habitaciones y en medicina como un complemento al tratamiento primario. La actividad antimicrobiana reside en sus propiedades oxidativas. También tienen un efecto sobre el metabolismo de los tejidos inflamados, activa la respuesta inmune del cuerpo y destruye las bacterias, hongos y virus. La exposición al ozono reduce los recuentos de bacterias Gram-positivas y Gram-negativas, así como de células de levadura (Candida albicans) ${ }^{26}$. El ozono produce la lisis de la pared bacteriana produciéndose la extravasación del contenido de células bacterianas. Al ingresar a la célula, el ozono promueve la oxidación de los ácidos nucleicos y amino ácidos; y al final la lisis celular ${ }^{27}$.

Luz ultravioleta. Las longitudes de onda de la luz con mayor efecto germicidas, son aquellas que caen dentro del ultravioleta, entre los 200 y $280 \mathrm{~nm}$; la irradiación emanada en ese rango se ha utilizado para la desinfección del aire y descontaminación de dispositivos médicos. Sin embargo se consideraba que la luz dentro del espectro visible ( 400 y $700 \mathrm{~nm})$ tenía poco efecto biocida; sin embargo las longitudes de onda de la luz violeta azul alrededor de $405 \mathrm{~nm}$, han demostrado poseer efectos antimicrobianos, lo que permite un nuevo espacio para el control de microorganismos en muchas áreas de aplicación ${ }^{28}$.

Descarga luminiscente de corriente continua. La descarga luminiscente de corriente continua es plasma que conduce electricidad y que se forma cuando la corriente eléctrica pasa entre dos electrodos metálicos en un medio que contiene el gas argón a baja presión y que a un voltaje determinado, se ioniza. Recientemente esta descarga de luz, ha despertado un gran interés porque puede ser utilizado para una amplia gama de aplicaciones, como la modificación de superficies mediante el depósito fino de película y también para descontaminación biológica. Dicho plasma se producen generalmente por diferentes tipos de descargas y es la descarga luminiscente de CC una de las más populares entre ellas ${ }^{29}$.

Autoclave de vapor. Es un dispositivo para esterilizar que funciona a alta presión de vapor saturado a $121^{\circ} \mathrm{C}$ y que utiliza tiempos que van de 15 a 20 minutos, siendo efectivo contra la mayoría de las bacterias, esporas, virus y hongos ${ }^{17}$.

Autoclave de gas de óxido de etileno. El procedimiento de esterilización con óxido de etileno se considera la última opción de los procedimientos de esterilización debido a la producción de residuos de gases tóxicos. El procedimiento de esterilización más recomendado es la esterilización en autoclave, procedimiento de esterilización por calor húmedo que son simples y no tienen residuos tóxicos; sin embargo, sigue siendo un agente de esterilización muy usado debido a su efectividad y compatibilidad con la mayoría de los materiales y la ausencia de calor y el estrés radiolítico asociados a la esterilización con vapor o radiación de rayos gamma. Esta técnica requiere cuidados especiales para la protección de los trabajadores y pacientes, lo que ha llevado a varios países a limitar su uso ${ }^{30}$.

Descarga de resplandor de radiofrecuencia de argón (RGD). El plasma es el $4^{\circ}$ estado de la materia, y es un estado altamente activo. Todo el universo se compone de estado de plasma excepto los planetas y sus satélites y es ampliamente utilizada para el tratamiento de superficies ya que mejora la energía superficial y la humectabilidad; esto se ha explorado para muchas aplicaciones, como modificaciones superficiales y aplicaciones biomédicas ${ }^{31}$.

La radiofrecuencia de argón, también ha sido utilizada en impresiones bucales, ya que su aplicación en ella puede esterilizar y mejorar simultáneamente la humectabilidad de la superficie de los materiales de impresión, tal como ha sido demostrado en investigaciones sobre aplicación de RGD en la superficie del material de impresión, ya sea no contaminado o contaminado con saliva, en comparación con la desinfección líquida convencional, con variados resultados, debido a las diferencias en la estructura polimérica superficial de los materiales de impresión, algunos resultados en siliconas por adición demostró una reducción significativa en el ángulo de contacto (mejora de la humectabilidad) ${ }^{32}$.

En la tabla 3 se resumen las principales características de los desinfectantes utilizados en los materiales de impresión dental.

Tabla 3. Desinfectantes utilizados en los materiales de impresión dental. Fuente: Adaptado de Mushtaq y Ullah ${ }^{17}$

\begin{tabular}{llc}
\hline \multicolumn{1}{c}{ Desinfectante } & \multicolumn{1}{c}{ Tipo } & $\begin{array}{c}\text { Concentración } \\
\text { recomendada }\end{array}$ \\
\hline Glutaraldehido & No oxidante & $2 \%$ \\
Hipoclorito de sodio & Oxidante & $0,5 \%$ o $200-5000 \mathrm{ppm}$ \\
Yodóforos & Oxidante & $1-2 \%$ \\
Alcoholes & No oxidante & $60-90 \%$ \\
Clorhexidina & No oxidante & $2-4 \%$ \\
Fenoles & No oxidante & $1-3 \%$ \\
\hline
\end{tabular}

ppm = partes por millón

\section{Consideraciones del uso de los desinfectantes para los materiales de impresión dental}

El control de la infección cruzada es de vital importancia en la práctica dental, pero la desinfección de impresiones sigue siendo un aspecto ampliamente descuidado. Los criterios adecuados para la desinfección de impresiones implican: el método más adecuado (pulverización o inmersión), aplicación adecuada (tiempo de contacto) y la comprobación periódica de eficacia ${ }^{17}$.

Los factores a considerar para cualquier protocolo de desinfección para la impresión dental son la efectividad, la estabilidad química y la eficacia de la solución desinfectante. El procedimiento de desinfección no debe alterar las dimensiones y los detalles de la superficie de la 
impresión y el modelo resultante. Se ha demostrado que el método más efectivo para reducir la carga de microorganismos de la superficie de impresión es la desinfección química ${ }^{22}$. La desinfección por pulverización y la desinfección por inmersión son dos métodos de desinfección de impresiones. Sin embargo, la inmersión es el método más confiable porque todas las superficies de impresión entran en contacto con la solución desinfectante ${ }^{25}$.

La fidelidad en la reproducción de las estructuras orales obtenidas mediante los materiales de impresión debe ser lo más cercana posible al modelo real para garantizar un correcto diagnóstico y tratamiento. Por ejemplo, en la especialidad de ortodoncia se toman modelos de estudio como examen auxiliar, para realizar mediciones y tratar de predecir el espacio necesario para el correcto alineamiento de las futuras piezas permanentes que erupcionarán en el recambio dentario.

El material de impresión usado para estos modelos de estudio es principalmente el hidrocoloide irreversible (alginato), por su bajo costo y fácil manejo; durante la práctica clínica el vaciado de estas impresiones suele ser inmediato, pero el proceso de desinfección de dichas impresiones suele obviarse debido a que se prioriza la fidelidad de los modelos en positivo (vaciado en yeso) antes que las normas de bioseguridad para estos casos. En esta situación, las personas que posteriormente manipulan la impresión quedan expuestas a una posible infección cruzada de distintas enfermedades que se pueden encontrar en algún resto de sangre que se pudo impregnar en la impresión ${ }^{10}$.

Para evitar la infección cruzada se debe desinfectar la impresión, hay distintas sustancias con las cuales se logra este objetivo, tales como el hipoclorito de sodio al $5 \%$ a través de aerosol o inmersión, el glutaraldehido al 2\%, la clorhexidina al 2\%, entre otras; como dichas sustancias vienen en presentación líquida, al ser aplicadas sobre el hidrocoloide irreversible (alginato) alterarán su estabilidad dimensional por el fenómeno de sinéresis.

Estudios previos encuentran que la desinfección por inmersión de las impresiones con hidrocoloide irreversible (alginato) altera la estabilidad dimensional, dependiendo del tipo de desinfectante, tiempo de inmersión, marca comercial de hidrocoloide irreversible (alginato). Estudios como los de Muzzafar y cols. ${ }^{11,15}$ y el de Herrera y cols. ${ }^{16}$ demuestran que se produce un cambio estadísticamente significativo sobre la estabilidad dimensional de impresiones con hidrocoloide irreversible (alginato) al ser sometido a la desinfección por inmersión.

El tema de la prevención de la transmisión de infecciones se ha vuelto de vital importancia en la práctica de la Odontología, debido al creciente entendimiento y conciencia de la contaminación cruzada con enfermedades como la hepatitis B y el virus de la inmunodeficiencia humana ${ }^{33}$. La transmisión de enfermedades ocurre debido al contacto con sangre y otros fluidos corporales, durante la manipulación de instrumentos e impresiones contaminadas en la ejecución de diversos procedimientos odontológicos, es por ello que la ADA (Asociación
Dental Americana) recomienda la desinfección y la esterilización de instrumentos y materiales dentales, incluidas las impresiones ${ }^{34}$. Debido a esto, se han recomendado diversos agentes desinfectantes para los materiales de impresión, los cuales, deberían ser compatibles con estos y no poseer un efecto adverso sobre la estabilidad dimensional y los detalles de la superficie de la impresión ${ }^{33}$. Los cambios dimensionales después de la desinfección pueden ser debidos a la naturaleza química del desinfectante y su reacción con el material de impresión ${ }^{35}$, por lo cual es muy importante el conocimiento de los diferentes agentes de desinfección y métodos utilizados.

Los efectos de los diversos agentes desinfectantes y procedimientos para su aplicación son variados, considerando el tipo de material de impresión y sus propiedades, la naturaleza del desinfectante y su efecto sobre esas propiedades, la forma y el tiempo de aplicación del agente, complejidad y costos del procedimiento. Entre las soluciones desinfectantes de alto grado está el glutaraldehido, el cual se recomienda usar al $2 \%$ o al 3,5\%. Entre los desinfectantes de grado medio, tenemos al hipoclorito de sodio, el cual se recomienda usar al 5,25\%; ambos por 10 minutos. También se recomienda soluciones de compuestos derivados del amonio cuaternario al $2 \%$ o soluciones de aldehído al 10\%. Los agentes físicos, si bien han demostrado actuar adecuadamente como desinfectantes, requieren una mayor inversión y procedimientos más complejos. El agua con alto contenido de cloro también tiene efectos desinfectantes, posterior al lavado de la impresión con agua se evidenció una disminución de 48,5\% de bacterias, y luego del uso de hipoclorito de sodio se observó una inhibición del crecimiento bacteriano del $99,99 \%{ }^{36}$.

El efecto desinfectante perdería valor si este produjera un cambio irreversible en las características de la impresión, y esto es un riesgo real para todos los materiales de impresión expuestos a los agentes desinfectantes. Las propiedades más involucradas son la estabilidad dimensional y la reproducción de detalles de las impresiones luego de ser desinfectados ${ }^{34}$. Los agentes químicos son los más fáciles de aplicar y al respecto, los alginatos, debido a su natural inestabilidad dimensional (imbibición y sinéresis), deben desinfectarse en el menor tiempo posible y no ser expuesto al agente por inmersión sino por pulverización o rociado, para disminuir el riesgo de alterar sus dimensiones y capacidad de reproducir detalles ${ }^{35}$.

Los alginatos son, tal vez, los materiales más usados y los que más riesgos de contaminación tienen, por ello el incremento de estudios referente a este hidrocoloide y los cambios en su estabilidad dimensional. En un estudio se determinó el efecto de dos soluciones desinfectantes (Perform ID/hipoclorito de sodio), sobre la estabilidad dimensional de dos tipos de alginato (Blueprint Cremix e Hydrogum); en ambos casos se evidenció diferentes grados de contracción del hidrocoloide siendo mayor en aquellos que presentaron un mayor grosor $(>3 \mathrm{~mm})^{37}$.

El efecto del hipoclorito de sodio sobre la estabilidad dimensional de las impresiones de alginato ha sido estudiado a diferentes concentraciones y usando métodos 
de aplicación por pulverización e inmersión, no observándose cambios dimensionales significativos en los modelos de yeso obtenidos de impresiones tratadas por rociado, a diferencia de los modelos obtenidos de impresiones tratadas por inmersión en los cuales se han reportado cambios en la precisión dimensional ${ }^{38}$. Además, tiempos de exposición de 20 y 30 minutos mediante la técnica de pulverización también han mostrado cambios dimensionales en el alginato ${ }^{39}$. Cabe mencionar la popularidad del uso del glutaraldehido para la desinfección de impresiones, sin embargo los bajos costos del hipoclorito de sodio y su acceso fácil hacen de éste último una gran alternativa en la desinfección de impresiones.

Los materiales elastoméricos (siliconas, poliéteres y polisulfuros), hidrófobos por naturaleza, permiten un mayor tiempo de exposición al agente desinfectante y un procedimiento por inmersión. Sin embargo, con los elastómeros hidrófilos es preferible aplicar con precaución los procedimientos, en cuanto al tiempo e inmersión de ellos, por su afinidad a los líquidos y potencial de absorción de líquidos. Cuando se ha estudiado los cambios dimensionales de los elastómeros al ser desinfectados glutaraldehído $2 \%$ e hipoclorito de sodio $0,525 \%$, se ha encontrado que el polivinilsiloxano presenta menores cambios respecto a los poliéteres ${ }^{40}$.

Algunos tipos de vinil polisiloxanos, son usados como alternativa a los alginatos y al ser sometidos a desinfección con compuestos clorados, han mostraron mejor estabilidad dimensional que los alginatos ${ }^{41}$. También han sido evaluados los efectos de los compuestos clorados sobre la reproducción de detalles y estabilidad dimensional de materiales de impresión elastoméricos, manteniendo, todos, un $100 \%$ de reproducción de detalles, independientemente del procedimiento de desinfección y de ellos los polisulfuros mostraron los valores medios más pequeños de estabilidad dimensional ${ }^{34}$. Los materiales a base de vinilpolisiloxano evidenciaron pequeños cambios dimensionales incluso luego de dos semanas de almacenamiento al ser desinfectados con glutaraldehído ${ }^{42}$.

Ahora bien, no solo la estabilidad dimensional es la única propiedad a cuidar de las impresiones, existen muchas otras que garantizan la exactitud de los modelos futuros; por ejemplo la reproducción de detalles finos durante la impresión, la cual depende de la humectabilidad de los materiales de impresión, expresados durante la toma de impresión, como la capacidad de mojar las estructuras impresionadas y durante el vaciado del modelo, permitiendo que el yeso moje la impresión, es decir sea hidrofílico; es por ello que para mejorar la hidrofilia del material de impresión se utilizan soluciones tensioactivas; sin embargo los efectos de los agentes humectantes aún no está claro sobre los cambios dimensionales en los materiales de impresión elastoméricos ${ }^{43-45}$.

Resolver el riesgo de las infecciones cruzadas y asegurar el éxito del tratamiento protésico a partir de impresiones bucales óptimas, nos obliga a conocer los distintos agentes y métodos de desinfección de las impresiones, para poder elegir la mejor alternativa que posibilite una desinfección adecuada, sin alterar significativamente las propiedades de las impresiones, lo cual resulte en un mejor servicio de salud bucal a los pacientes. Se recomienda que los dentistas peguen etiquetas en las impresiones que son enviadas a laboratorios dentales indicando el estado de desinfección de las impresiones. La desinfección repetitiva de impresiones plantea el riesgo de cambios en la estabilidad dimensional y reproducción de detalles de superficie, en ese sentido la comunicación entre dentistas y los técnicos dentales a este respecto son esenciales.

\section{Conclusiones}

La desinfección de las impresiones bucales es de suma importancia para evitar los riesgos de contaminación cruzada. Se debe considerar la acción desinfectante del agente, sus efectos sobre la estabilidad dimensional y la reproducción de detalles de las impresiones, las cuales se ven más afectadas con el aumento del tiempo de exposición al agente. El uso de un desinfectante de nivel medio es recomendado por la Asociación Dental Americana, siendo los agentes químicos más accesibles que los agentes físicos por su fácil aplicación y menor costo. El desinfectante más recomendado es el hipoclorito de sodio al $0,525 \%$, debido a sus mínimas interacciones, su bajo precio y, aunque la solución es poco estable, su renovación es fácil y económica.

\section{Referencias bibliográficas}

1. British Dental Association. Health Technical Memorandum 01-05: Decontamination in Primary Care Dental Practices. London: Department of Health; 2013.

2. 4 Garn RJ, Sellen PN. Health and safety in the laboratory. Dent Tech. 1992;45(1):103-120.

3. Leung RL, Schonfeld SE. Gypsum casts as apotential source of microbial cross-contamination. J Prosthet Dent. 1983;49(2):210-211. DOI:10.1016/00223913(83)90503-6

4. Kugel G, Perry RD, Ferrari M, Lalicata P. Disinfection and communication practices: asurvey of U.S.dental laboratories. JAm Dent Assoc. 2000;131:786-792. DOI:10.14219/jada.archive.2000.0278

5. Sofou A, Lasren T, Fiehn N, Owall B. Contamination level of alginate impressions arriving at adental laboratory. Clin Oral Invest. 2002;6:161-165.

6. Demajo JK, Cassar V, Farrugia C, Millan-Sango D, Sammut C, Valdramidis V, Camilleri J. Effectiveness of disinfectants on antimicrobial and physical properties of dental impression materials. Int J Prosthodont. 2016;29(1):63-67. DOI:10.11607/ijp.4358

7. Lepe X, Johnson GH, Berg JC. Surface characteristics of polyether and addition silicone impression materials after long-term disinfection. J Prosthet Dent. 1995;74(2):181-186. DOI:10.1016/S0022-3913 (05)80184-2

8. Flanagan DA, Palenik CJ, Setcos JC, Miller CH. Antimicrobial activities of dental impression materials1 Most of the research data present in this manuscript was presented as an abstract on March 13, 1994 at the International Association for Dental Research Annual 
Research Session, held in Seattle, WA. Dent Mater 1998;14(6):399-404.

9. Briceño AMS, Castillo GAR, Nachón GMG, González OSA, Carmona CDA, Ortega PCB, Escobar CP, Izquierdo JJ. Prevalencia de microorganismos en impresiones dentales después del uso de soluciones desinfectantes. Revi Med Universidad Veracruzana. 2014;14(1):27-32.

10. Thouati A, Deveaux E, Iost A, Behin P. Dimensional stability of seven elastomeric impresion materials inmersed in disinfectans. J Prosthet Dent. 1996;76(1):8-14.

11. Muzzafar D, Braden M, Parker S, Patel M. The effect of disinfecting solutions on the dimensional stability of dental alginate impression materials. Dent Materials. 2012;28:749-755.

12. Moreira, Anaya SR. Modificadores De Materiales Dentales. Rev Act Clin. 2013;30:1525-8.

13. Cárdenas-Rodríguez S. Manejo y características de los materiales de impresión más utilizados en el área restauradora. Universidad de Guayaquil. Facultad Piloto de Odontología; 2013.

14. Ayaviri-Pérez RC, Bustamante C G. Alginato. Rev Act Clin Med. 2013;30(10):557-64.

15. Muzzafar D, Ahsan SH, Afaq A. Dimensional changes in alginate impression during immersion in a disinfectant solution. J Pak Med Assoc. 2011;61(8):756-759.

16. Herrera SP, Merchant VA. Dimensional stability of dental impressions after inmersión disinfection. JADA. 1986;113(1):419-422.

17. Mushtaq MA, Ullah MW. An Overview of Dental Impression Disinfection Techniques A Literature Review. J Pakistan Dent Assoc [Internet]. [Consultado el 22 de noviembre del 2019]. Disponible en: http://www.jpda. com.pk/an-overview-of-dental-impression-disinfection-techniques-a-literature-review-2/

18. Stiles ME, Sheena AZ. Efficacy of low-concentration iodophors for germicidal hand washing. J Hyg (Lond). 1985;94(3):269-77.

19. Capriotti K, Capriotti J. Topical iodophor preparations: Chemistry, microbiology, and clinical utility. Dermatol Online J. 2012;18(11):1.

20. Sehmi SK, Allan E, MacRobert AJ, Parkin I. The bactericidal activity of glutaraldehyde-impregnated polyurethane. Microbiologyopen. 2016;5(5):891-7.

21. Neelakantan P, Herrera DR, Pecorari V, Gomes BPFA. Endotoxin levels after chemomechanical preparation of root canals with sodium hypochlorite or chlorhexidine: A systematic review of clinical trials and meta-analysis. Int Endod J. 2019;52(1):19-27.

22. Pradhan MS, Gunwal M, Shenoi P, Sonarkar S, Bhattacharya S, Badole G. Evaluation of $\mathrm{pH}$ and Chlorine Content of a Novel Herbal Sodium Hypochlorite for Root Canal Disinfection: An Experimental In vitro Study. Contemp Clin Dent. 2018; 9(Suppl 1):S74-8.

23. Unković N, Ljaljević Grbić M, Stupar M, Vukojević J, Janković V, Jović D, et al. Aspergilli response to benzalkonium chloride and novel-synthesized fullerenol/ benzalkonium chloride nanocomposite. Sci World J. 2015;2015:1-11.
24. Mallik R, Raman S, Liang X, Grobin AW, Choudhury D. Development and validation of a rapid ultra-high performance liquid chromatography method for the assay of benzalkonium chloride using a quality-by-design approach. J Chromatogr A. 2015;1413:22-32.

25. Matthijs S, Adriaens PA. Chlorhexidine varnishes: A review. J Clin Periodontol. 2002;29(1):1-8.

26. Bialoszewski D, Pietruczuk-Padzik A, Kalicinska A, Bocian E, Czajkowska M, Bukowska B, et al. Activity of ozonated water and ozone against Staphylococcus aureus and Pseudomonas aeruginosa biofilms. Med Sci Monit. 2011;17(11):BR339-BR344.

27. Ximenes M, Cardoso M, Astorga F, Arnold R, Pimenta LA, Viera R de S. Antimicrobial activity of ozone and $\mathrm{NaF}$-chlorhexidine on early childhood caries. Braz Oral Res. 2017;31:e2.

28. Maclean M, McKenzie K, Anderson JG, Gettinby G, MacGregor SJ. $405 \mathrm{Nm}$ Light Technology for the Inactivation of Pathogens and Its Potential Role for Environmental Disinfection and Infection Control. J Hosp Infect. 2014;88(1):1-11.

29. Jiang W, Tang J, Wang Y, Zhao W, Duan Y. Characterization of argon direct-current glow discharge with a longitudinal electric field applied at ambient air. Sci Rep. 2014;4:1-6

30. Shintani H. Ethylene Oxide Gas Sterilization of Medical Devices. Biocontrol Sci. 2017;22(1):1-16.

31. Jain V, Visani A, Srinivasan R, Agarwal V. Design and development of a low cost, high current density power supply for streamer free atmospheric pressure DBD plasma generation in air. Rev Sci Instrum. 2018;89(3). DOI: $10.1063 / 1.4993312$.

32. Hesby RM, Haganman CR, Stanford CM. Effects of radiofrequency glow discharge on impression material surface wettability. J Prosthet Dent. 1997;77(4):414-22.

33. Savabi O, Neatidanesh F, Poshang Bagheri K, Karimi L, Savabi G. Prevention of Cross-contamination Risk by Disinfection of Irreversible Hydrocolloid Impression Materials with Ozonated Water. Int J Prev Med. 2018;9(37):1-5.

34. Guiraldo RD, Berger SB, Punhagui MF, Moretto TS, Lopez MB, Gonini-Junior A, et al. Effectiveness of platelet-rich fibrin in the management of pain and delayed wound healing. Eur J Dent. 2018;12(2):232-6.

35. Kalantari MH, Malekzadeh A, Emami A. The Effect of Disinfection with Sodium Hypochlorite $0.5 \%$ on Dimensional Stability of Condensation Silicone Impression Materials of Speedex and Irasil. J Dent Shiraz Univ Med Sci J Dent Shiraz Univ Med Sci. 2014;15(153):98-103.

36. Correia-sousa J, Tabaio AM, Silva A, Pereira T, Sampaio-maia B, Vasconcelos M. The effect of water and sodium hypochlorite disinfection on alginate impressions. Rev Port Estomatol Med Dentária e Cir Maxilofac. Sociedade Portuguesa de Estomatologia e Medicina Dentária; 2013;54(1):8-12.

37. Muzaffar D, Braden M, Parker S, Patel MP. The effect of disinfecting solutions on the dimensional stability of dental alginate impression materials. Dent Mater. 2012;28(7):749-55. 
38. Babiker GH, Khalifa N, Alhajj M. Dimensional Accuracy of Alginate Impressions Using Different Methods of Disinfection With Varying Concentrations. Compend Contin Educ Dent. 2018;39(1):e17-20.

39. Dreesen K, Kellens A, Wevers M, Thilakarathne PJ, Willems $\mathrm{G}$. The influence of mixing methods and disinfectant on the physical properties of alginate impression materials. Eur J Orthod. 2013;35:381-7.

40. Khinnavar PK, Kumar BHD, Nandeeshwar DB. An in vitro study to evaluate the effect on dimensional changes of elastomers during cold sterilization. J Indian Prosthodont Soc. 2015;15(2):131-7.

41. Suprono MS, Kattadiyil MT, Goodacre CJ, Winer MS. Effect of disinfection on irreversible hydrocolloid and alternative impression materials and the resultant gypsum casts. J Prosthet Dent. 2012;108(4):250-8.
42. Nassar U, Flores-Mir C, Heo G, Torrealba Y. The effect of prolonged storage and disinfection on the dimensional stability of 5 vinyl polyether silicone impression materials. J Adv Prosthodont. 2017;9:182-7.

43. Lad PP, Gurjar M, Gunda S, Gurjar V, Rao NK. The Effect of Disinfectants and a Surface Wetting Agent on the Wettability of Elastomeric Impression Materials: An In Vitro Study. J Int Oral Heal. 2015;7:80-3.

44. Hemalatha R, Ganapathy D. Disinfection of dental impression. A current overview. J Pharm Sci Res Cuddalore. 2016;8(7):661-664.

45. Demajo JK, Cassar V, Farrugia C, Millan-Sango D, Sammut C, Valdramidis V, Camilleri J. Effectiveness of disinfectants on antimicrobial and physical properties of dental impression materials. Int J Prosthodont. 2016;29(1):63-67. 
